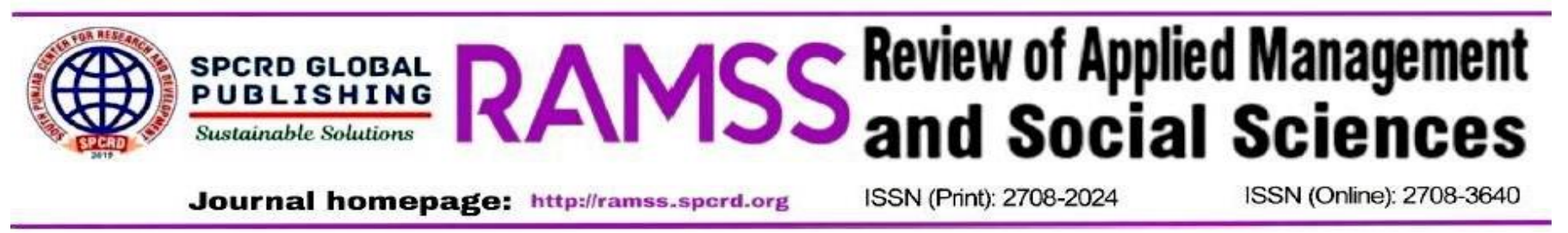

\title{
Monitoring and Evaluation System in Education: An Overview of Elementary Schools
}

\author{
${ }^{a}$ Muhammad Latif Javed, ${ }^{b}$ Mehwish Inayat, ${ }^{c}$ Muhammad Nadeem Javed \\ ${ }^{a}$ Assistant Professor, Department of Education, The Islamia University of Bahawalpur, Bahawalnagar, \\ Pakistan \\ Email: latif.javed@iub.edu.pk \\ ${ }^{\mathrm{b}}$ Assistant Education Officer (AEO), School Education Department, Bahawalnagar, Punjab, Pakistan \\ Email: Mehwish403@gmail.com \\ ${ }^{\mathrm{c}}$ Visiting Lecturer, Mirpur University of Science \& Technology, Azad Jammu \& Kashmir, (AJ\&K) \\ Email: nadeemjavedo5@gmail.com
}

\begin{tabular}{l}
\hline ARTICLE DETAILS \\
\hline History: \\
Accepted o5 November 2021 \\
Available Online December 2021
\end{tabular}

\section{Keywords:}

Usefulness of Monitoring and

Evaluation, Educational

Administers and Manager's

Performance

\section{JEL Classification:} $P_{3} 6$

DOI: $10.47067 /$ ramss.v4i4.187

\begin{abstract}
This research study aims to discuss and analyse the current monitoring and evaluation practices at elementary schools in Punjab. The main objective of this study was to know the usefulness of monitoring and evaluation system and to investigate how the teachers and administrators perceive school effectiveness through monitoring and evaluation system. This study is helpful for the educational leaders to know the advantages and disadvantages of monitoring system. Elementary school teachers (4013) of district Bahawalnagar were the population of this study. The sample of the study was selected by using multistage sampling technique. A thorough review of literature was carried out to develop relevant data collection tools. A questionnaire with five-point Likert scale was developed to record the responses of the participants of the study. The questionnaire was constructed with the statements about determinants for monitoring and evaluation in system of education at elementary school level. Quantitative data was collected and analysed using descriptive statistics e.g., mean, and standard deviation through computer software SPSS-21. A questionnaire comprised of 19 statements including two objectives was devised as a research tool. The findings and conclusion of the study related to effectiveness found that monitoring system for the evaluation of the schools is working partly. The analysis of the data revealed that the monitoring and evaluation system is helpful in enhancing total school performance. However, still there are some gaps in the system which needs to be plugged in. The participants proposed to revise the mechanism of monitoring.
\end{abstract}

(C) 2021 The authors. Published by SPCRD Global Publishing. This is an open-access article under the Creative Commons Attribution-

NonCommercial 4.0 


\section{Introduction}

Education is one of the key components for an individual's and a nation success. It can shape one's life in the righteous direction. Education is a process of conveying or gaining knowledge, evolving the powers of cognition and verdict. It prepares oneself intellectually for developed life. It improves personal and social lives of the people. Education has foremost important place in the development of nations. The school establishments became the sign of changes and revolutions within the industrialized world.

The Government of Pakistan time to time tried its best to make sure the needs and ambitions of individuals and society as well. During this view, more than a few steps are taken to make sure, both the material and the human resources are placed jointly to get the right settlement of education. In the modern age, the schools have become federation of revolution. Monitoring and evaluation $(M \& E)$ are the best gadgets for the measurement of quality assurance in education. M\&E provides us with the base for enquiring and testing expectations. The definition of monitoring used in this study is consistent with one which is maintained by the department of Monitoring Planning and Evaluation (DPME, 2004).

In the educational system, monitoring enfolds actions of reviewing and regulation (Khawaja, 2001). The constant assessment of project execution in relation to approved agendas and of use of inputs, set-up, and services by project recipients (Mertens, 2005). Monitoring is a type of valuation that gathers actual shreds of evidence used for program reformation (Noh, 2006). The Devolution Plan (2000) devolved powers and responsibilities, including those related to social services, from the provincial levels to elected and selected district level authorities and local councils. Under devolution, political power, decision-making authority, and administrative responsibilities were moved as close as possible to the village, union council, Tehsil, and district levels, whereas the major policy making, coordination, and special service functions were left with the provincial governments. Levels of devolution were: Electoral transference through the establishment of elected local government.

- Financial federalization through the transfer of funds to local government.

- Organizational devolution, to keep up some correspondence with the new delegated electoral and fiscal measures.

Under transference, there was a shift of charge, from provincial to district government. As in an educational system it is performed by various external officers and officials. In the Punjab School Education Department (PSED) after the decentralization of powers, activities are being supervised by the district government. Chief Executive Officers (CEOs) and District Education Officer (DEOs) at district level, Deputy District Education Officer (Dy. DEOs) at Tehsil level, and Assistant Education Officers (AEOs) at Markaz level are recruited and appointed for supervising the entities of the educational system. Monitoring and Evaluation officials are posted there for real time monitoring

This study was aimed to find usefulness of the monitoring and evaluation system being practiced in our schools and to illustrate perceptions of teachers and administrators being evaluated by this system of monitoring and evaluation.

The main objective of this research study was to analyse the effectiveness of monitoring and evaluation in schools of Punjab, whereas the specific objectives of the study are: 
1. To explore the usefulness of monitoring and evaluation for school improvement.

2. To investigate the perceptions of administrators and teachers about the role of real-time monitoring and evaluation.

Based on the objectives of the research, the followings are the study questions.

1. What is the effectiveness of the monitoring and evaluation systems in schools?

2. What are the weaknesses of this monitoring and evaluation system of schools?

3. What perception do teachers and administrators hold about a system of monitoring and evaluation of schools?

This research was significant for the teachers, administrators, and policymakers to know about the weaknesses of the monitoring and evaluation systems. They could be able to know the gaps in expectations and reality through self-analysis. The teachers can also get profited from this study and make corrections. The policymakers may overcome the niche by designing better policies.

\section{Literature Review}

This part of research study is to review the related literature to discuss its background, status, and future implications in the system of education at School level. The literature was reviewed from books, research thesis, articles and research work published in different journals at national and international level.

\subsection{MONITORING}

Monitoring is a wide-ranging impression, and it has brought various names and roles in various formations. Monitoring is a procedure of collecting of pieces of evidence at even breaks about enduring programs of school to offer feedback (Shah, 2009). Monitoring is an orderly and ongoing procedure of gathering and evaluating information that provides supervision of an unending interference with primary suggestions of progress, or deficiency, therefore, in the accomplishment of results (Bartle, 2010; UNAIDS, 2010; UNEP, 2010).

\subsection{EVALUATION}

Evaluation is estimation or determining the value of something. So, these processes are used in the field of education very often to test the quality of teaching and learning processes. Referring to Thorndike and Hagan, evaluation is closely related to extent. It is in around respect, comprehensive including informal and instinctive judgement of pupil's progress. Evaluation is relating something in term of attributes and judging the degree of adequacy or appropriateness of that which has been described.

\subsection{MONitoring AND Evaluation}

Monitoring and evaluation are twofold equal conditions as for the most part these two terms are utilized together. As it is identified that there is a solitary post for checking and valuation official in the greater part of the association. We should peep into the two ideas.

i. Monitoring is an action that includes constant and precise examination and seeing of a scheme or an undertaking. The Assessment then again is judging, checking on, or characterizing the value, the worth, and greatness of a program. It includes contrasting the current circumstance and the past to discover the degree to which the set down goals have been accomplished (Handbook for the examination of instructive organizations, 2000). 
ii. Monitoring and assessment are done in the instruction part to tour the projects like the nature of training. In training two exercises happen these are showing completed through the instructors and getting learned by the understudies. Educators who instruct in auxiliary schools are generally extent or confirmation holders in training. All through preparing the instructors' experience systems of educating and are accordingly knowledgeable with great instructing rehearses. The chief is liable for observing and assessment at the school stage to guarantee powerful educating and learning is continued (Williams, 2000).

\subsection{Internal Monitoring of Education in Punjab}

According to Ali, N., Sharma, S., \& Zaman, A. (2017), in the present level of school culture in the stated schools is low and there is a significant relationship between school culture and school effectiveness. It was concluded that high level of school culture will help achieve high the level of school effectiveness.

In the training history of Pakistan, there is just the Internal Monitoring System. It is likewise named as a departmental Monitoring System. Delivering to this framework, the superintendent is an immediate administrator of the school and responsible to keep the school program on the given track. Close by this, Executive District Officers (EDOs), District Education Officers (DEOs), and Deputy District Education Officers (Dy. DEOs) are in charge for regulatory anticipating observing and advancement (Mahmood, 2017).

Corridor and Hoard's (2015) phases uncovered those recognitions to change can change after some time and increment positively. This suggests the requirement for persistence and comprehension for those executing the change. Positive adjustment isn't tied in with forcing educators to follow the new orders. It is more about allowing educators to reflect solely and together, subsequently constructing certainty, sharing thoughts, welcoming fortitude, and causing insight of the change so they too can join the change into their expert does such that sounds good to them by and by (Price, 2012). This requires significant investment and persistence.

The final leadership and organizational theorists reviewed are Bolman and Deal (2008). Bolman and Deal (2008) talk about administration with regards to reassessing or intentionally seeing a circumstance from numerous points of view" (p. 37) and offer the human asset outline as one viewpoint. "HR scholars normally advocate receptiveness, commonality, tuning in, training, interest and strengthening" (p. 41); these characteristics are at the core of smaller than expected perceptions. The management procedure shifts from the setting of assessments and documentation of execution to that of intelligent discussion where the director poses inquiries and tunes in, to help the instructor's expert development. Bolman and Deal (2008) articulate that "HR Leaders Are Visible and Accessible" (p. 41) is one of three initiative standards.

Thousand years Development Goals (MDGs) which became an integral factor in the period the 20oos further grasped Monitoring and Evaluation Systems. The MDG targets were converted into a lot of pointers that could gauge progress. In the ongoing past, there has been a lot of spotlights on a results-based methodology that has a few components of Monitoring and Evaluation, for instance decreasing neediness and enhancing expectations for everyday comforts of individuals (Zhou \&Hardlife, 2013). 
Observing and assessment frameworks in this manner can be believed to have establishes in results-based administration draws near. Kusek \&Rist (2004) noticed that outcomes-based methodology utilizes both the conventional ways to deal with M\&E, simultaneously permitting estimations of results. The attention on results can be named as the M\&E frameworks and has picked up fame among numerous associations around the globe (Göergens, and Kusek 2009).

\subsection{EXTERnal Monitoring of EdUCATION IN PUNJAB}

As per the International Monetary Fund (IMF,2015a), Monitoring and Evaluation Systems empower both the private and open area to precisely survey the exercises and as such this upgrades responsibility, adequacy, and proficiency of the advancement program embraced, which will mean the acknowledgment of Sustainable Development Goals (SDGs) because IMF has a dedication which is the extent of its activity to the worldwide organization for SDGs.

Globalization has decreased the world into a little town and, in this manner, more interconnectedness, which calls for governments and associations to be more responsible, display great administration as a way to deal with acknowledging improved turn of events. Kusek \&Rist (2001), World Bank (2009), UNAIDS, (2009).

Observing and Evaluation has advanced after some time because of the requirement for Results-Based Management (RBM) just as restricted assets and association of non-state entertainers being developed (Kusek and Rist, 2001). About the IMF (2015a), organizations and governments need appropriate and incredible Monitoring and Evaluation Systems to deal with acknowledging reasonable program administration and responsibility. Barely any content that the old arrangement of assessment, where educators were either never or occasionally assessed or where all instructors were esteemed acceptable, was satisfactory (Papay, 2012). Many concur that current assessment frameworks that numerous areas have had set up are ineffectual. Assessments that don't occur or occur in a rushed or "fly-in" style fill little need; perceptions with no productive criticism are not addressing the necessities of educators or understudies (Papay, 2012).

PMIU is functioning under the managerial oversee of secretary instruction. The ground works are locked in on the agreement premise. They are given a motorbike to observe the field. They are named as Monitoring and Evaluation Assistants (MEAs). Measurements are gathered on prearranged document. The gathered information is putted and dealt with on an ordinary premise. Duplicates of watched data are sent to PMIU month to month for the coalition at the commonplace level. Duplicates of the month-to-month valuation reports are likewise sent to Chief Executive Officers (District Education Authority) for making the required move (Shah, 2009).

\section{Methodology}

In this section methodology of the research is explained. The intention of this study was to know the perceptions of schoolteacher, head of the schoolteachers and the administrators about system of monitoring and evaluation. The literature review sets a context of how schools are affected by monitoring and evaluation system

\subsection{Type AND NATURE OF RESEARCH}

The study was based on multistage sampling technique. Quantitative method was used in this research. Quantitative research relates to a positivistic method which grasps that neutral information can be derived only from shortest reflection or experience (Robson, 2002). 


\subsection{RESEARCH DESIGN}

This research was conducted to explore effectiveness of the system of monitoring and evaluation of schools, and to analyse the insights of teachers and managers. This is the descriptive type of study in which survey method was used to collect data. This research was conducted to find out effectiveness of monitoring system and to know the perceptions of the people being evaluated under this system in the Elementary Schools of District Bahawalnagar.

\subsection{POPUlation}

Rendering to Orodho (2008), targeted population is considered as entities from a genuine or hypothetic system of individuals, cases, or foci to which as analyst wishes to sum up the outcomes of the analysis. The population of this study was comprised of all District Education Officers (Male and Female), District monitoring officer (DMO), all Deputy District Education Officers (Male and Female), Head of the schoolteachers (HTs), and the schoolteachers working in Elementary school (Male and Female) of district Bahawalnagar.

\subsection{SAmple Size AND SAMPling Technique}

The sample was selected using multistage sampling. First, study was delimited to one district of Punjab, Bahawalnagar. Then by using convenient sampling, Tehsil Haroon Abad was selected. On third stage, out of 400 schools of tehsil, 79 schools were selected through convenient sampling. At fourth stage, three teachers from every sampled elementary schools were targeted as sample by using simple random sampling. Sample size was comprised of 237 headteacher and teachers (79 males and 158 females) teachers from public schools. There are total 363 (Male and Female) elementary schools in District Bahawalnagar out of which 146 are Male schools and 217 are Female schools. In those 363 , schools there are 4013 teachers. A sampling frame was developed for this purpose.

\subsection{Delimitation OF STUdY}

The research was bordered to only one tehsil of district Bahawalnagar. Including 237 schoolteachers (9o male teacher and 147 female teachers) from all 79 elementary schools of tehsil Haroonabad were counted in in sample of the study.

\subsection{RESEARCH INSTRUMENTATION}

The research tool used to gather data for the study was the questionnaire. The quantitative data were collected by using questionnaire. Rendering to Collins (2011) reviews and surveys, which are usually quantitative tools, can also be used in concurrence with qualitative approaches to deliver rationale and helpful indication. Following composition was used as an instrument.

1. The opinions of participants were studied through five points Likert scale questionnaires. (Likert scale was coded as $1=$ Strongly disagree, 2 =Disagree, 3 =Neutral, 4=Agree, 5 =Strongly Agree).

Questionnaire was constructed for the head of the schoolteachers and the teachers at elementary schools, which was consisting 19 statements. These statements were further divided into two factors. The questionnaire was translated into Urdu and provided to head of the schoolteachers for ease to get a proper understanding of the questions. The survey instrument was developed to get information on the following major themes. 
- Effectiveness of Monitoring and Evaluation (M\&E) System

Ten statements were developed about efficacy of M\&E system. Those statements were covering the operational definition of effective schools.

- Perception of Head of the Schoolteachers and Teachers

Nine statements were developed under this theme. These statements were regarding practice of M\&E system and insights of participants about them.

\subsection{Reliability and Validity of Instruments}

The reliability of research tool (19 statements) was calculated through SPSS 21.0 software, and it was 0.901. For validity of the instrument, it was tested on a small group of respondents which were not part of the sample. After finding the results and opinion of the experts the tool was improved and validated for the study.

\subsection{DATA Collection}

For Quantitative data, the researcher visited 30 elementary schools for collection of data. Where personal visits were not possible, 120 questionnaires were posted to the concerned AEOs.

\subsection{ANALYSIS OF DATA}

Data were examined by using SPSS 21.0 statistical software package. Descriptive statistics mean and Standard Deviation (SD) were calculated. At the end of the survey, it was required to report the discoveries in a meaningful form so that tendencies evolving from the statistics could be understood (Cohen, et al., 2011).

\section{RESULTS}

The sample of the study was 79 elementary schools located in Tehsil Haroon Abad. For purpose of information collection, questionnaires were used in head of the schoolteachers and teachers at elementary schools. The first part of the questionnaire included information regarding academic qualification, professional qualification, experience, and age.

The very $2^{\text {nd }}$ part of the questionnaire was about system of monitoring and evaluation (M\&E). There are two factors regarding system of M\&E such as effectiveness, perceptions of participants and practitioners regarding M\&E system. Data were collected through questionnaire and carefully originated, classified, tabulated, and interpreted through SPSS-21. 
Review of Applied Management and Social Sciences (RAMSS) Vol. 4, (4) 2021, 837 - 847

Table 01: Responses of the respondents about effectiveness of M\&E system and Perception of People being evaluated through the system.

\begin{tabular}{|c|c|c|c|c|c|c|c|}
\hline SN & Items & $\begin{array}{l}\text { Frq \& } \\
\text { \%age SA }\end{array}$ & $\begin{array}{l}\text { Frq \& \%age } \\
\text { A }\end{array}$ & $\begin{array}{ll}\text { Frq } & \& \\
\text { \%age } & \mathrm{N}\end{array}$ & $\begin{array}{ll}\text { Frq \& } \\
\text { \%age } \\
\text { DA }\end{array}$ & $\begin{array}{ll}\text { Frq } \quad \& \\
\text { \%age } \\
\text { SDA }\end{array}$ & Mean $\neq$ SD \\
\hline 1 & $\begin{array}{l}\text { Performance of } \\
\text { schools' }\end{array}$ & $2(0.8)$ & $5(2.1)$ & $19(8.0)$ & $84(35 \cdot 4)$ & $128(53.6)$ & $1.61 \pm 0.80$ \\
\hline 2 & $\begin{array}{l}\text { Teacher } \\
\text { presence }\end{array}$ & $8(3.4)$ & $11(4.6)$ & $39(16.5)$ & $\begin{array}{l}102(43.0 \\
)\end{array}$ & $77(32.5)$ & $2.03 \pm 1.00$ \\
\hline 3 & $\begin{array}{l}\text { Students' } \\
\text { attendance }\end{array}$ & $2(0.8)$ & $18(7.6)$ & $34(14 \cdot 3)$ & $85(35 \cdot 9)$ & $98(41.4)$ & $1.09 \pm 0.97$ \\
\hline 4 & $\begin{array}{l}\text { Number of } \\
\text { students without } \\
\text { uniforms }\end{array}$ & $4(1.7)$ & $42(17.7)$ & $69(29.1)$ & $64(27.0)$ & $58(24.5)$ & $2.45 \pm 1.09$ \\
\hline 5 & $\begin{array}{l}\text { Neatness of } \\
\text { students }\end{array}$ & $9(3.8)$ & $41(17 \cdot 3)$ & $40(16.9)$ & $95(40.1)$ & $52(21.9)$ & $2.43 \pm 1.45$ \\
\hline 6 & $\begin{array}{l}\text { Quality of } \\
\text { education }\end{array}$ & 21(8.9) & $63(26.6)$ & $42(17.7)$ & $53(22.5)$ & $58(24.5)$ & $2.73 \pm 1.33$ \\
\hline 7 & Record keeping & $20(8.4)$ & $17(7.2)$ & $48(20.3)$ & $93(39.2)$ & $59(24.9)$ & $2.35 \pm 1.18$ \\
\hline 8 & $\begin{array}{l}\text { Utilization of } \\
\text { funds }\end{array}$ & 21(8.9) & $28(11.8)$ & $46(19 \cdot 4)$ & $84(35 \cdot 4)$ & $58(24 \cdot 5)$ & $2.45 \pm 1.23$ \\
\hline 9 & School hygiene & $1(0.3)$ & $19(5.9)$ & $50(21.1)$ & $83(35)$ & $55(23.2)$ & $2.47 \pm 1.21$ \\
\hline 10 & $\begin{array}{l}\begin{array}{l}\text { Trust of stake } \\
\text { holders over } \\
\text { public schools. }\end{array} \\
\end{array}$ & $14(5.9)$ & $33(13.9)$ & $55(23 \cdot 3)$ & $71(30.0)$ & $64(27)$ & $2.42 \pm 1.19$ \\
\hline 11 & $\begin{array}{l}\text { Standards } \\
\text { Operating } \\
\text { Procedures } \\
\text { (SOPs) of } \\
\text { monitoring }\end{array}$ & $4(1.7)$ & $17(7.2)$ & $29(12.2)$ & $\begin{array}{l}90(38.0 . \\
)\end{array}$ & $97(40.9)$ & $1.91 \pm 0.98$ \\
\hline 12 & $\begin{array}{l}\text { Communication } \\
\text { of monitoring } \\
\text { SOPs }\end{array}$ & $3(1.3)$ & $39(16.5)$ & $70(29 \cdot 5)$ & 9740.9) & $28(11.8)$ & $2.54 \pm 0.95$ \\
\hline 13 & Practice of SOPs & $7(3.0)$ & $30(12.7)$ & $62(26.2)$ & $67(28.3)$ & $71(30.0)$ & $2.30 \pm 1.12$ \\
\hline 14 & $\begin{array}{l}\text { Assessment of } \\
\text { quality } \\
\text { education }\end{array}$ & $13(5 \cdot 5)$ & $49(20.7)$ & $48(20.3)$ & $73(30.8)$ & $54(22.8)$ & $2.55 \pm 1.20$ \\
\hline 15 & $\begin{array}{l}\text { School } \\
\text { cleanliness }\end{array}$ & $32(13.5$ & $3615.2)$ & $51(21.5)$ & $64(27.0)$ & $54(22.8)$ & $2.70 \pm 1.34$ \\
\hline 16 & $\begin{array}{l}\text { Officials' } \\
\text { behaviour }\end{array}$ & $20(8.4)$ & $42(17 \cdot 3)$ & $39(16.5)$ & $67(28.3)$ & $70(29.5)$ & $2.47 \pm 1.30$ \\
\hline 17 & Objectivity & $32(13.5)$ & $55(23.2)$ & $48(20.3)$ & $43(18.1)$ & $60(25.3)$ & $2.86 \pm 1.35$ \\
\hline
\end{tabular}


Review of Applied Management and Social Sciences (RAMSS) Vol. 4, (4) 2021, 837 - 847

\begin{tabular}{|l|l|l|l|l|l|l|l|}
\hline & $\begin{array}{l}\text { evaluation } \\
\text { report }\end{array}$ & & & & & & \\
\hline 18 & $\begin{array}{l}\text { Effect of physical } \\
\text { circumstances }\end{array}$ & $11(4.6)$ & $50(21.1)$ & $57(24.1)$ & $61(25 \cdot 7)$ & $58(24.5)$ & $2.56 \pm 1.20$ \\
\hline 19 & $\begin{array}{l}\text { Support of } \\
\text { department }\end{array}$ & $34(14 \cdot 3)$ & $33(13.9)$ & $46(19.4)$ & $73(30.8)$ & $51(21.5)$ & $2.69 \pm 1.34$ \\
\hline
\end{tabular}

From Table 01, it is clearly inferred that, A huge proportion of the respondents were strongly agreed on the improvement of schools' performance and improved teacher presence because of monitoring system. Most of the sampled respondents has strongly agreed upon improved student's attendance, decreased number of students who come to school without uniform and pupil's cleanliness. Majority of the respondents have agreed with usefulness of role of monitoring regarding quality of education, better record keeping, transparent usage of funds, school hygiene and developed trust of stakeholders over public schools.

According to most of the targeted respondents the filed officials have a pre-defined set of standards to follow and prior communication of those SOPs with lower hierarchy. Bulk of respondents have reported the authoritative behaviour of officials during their visit for monitoring purpose at schools. How objectivity of field report was widely accepted. According to the data collected from field departmental support in case of grievance was unremarkable.

\section{CONCLUSION}

The following conclusions were drawn grounded on findings of the research:

1. Performance of public schools and trust of stake holders over public schools has been increased because of the monitoring and evaluation (M\&E) practice.

2. Teacher's absenteeism has been eliminated.

3. Students' attendance and enrolment has been increased and retention was also maintained.

4. Due to practice of monitoring and evaluation student's punctuality and neatness has been improved.

5. Conduct of assessment tests has improved the quality education.

6. The system of monitoring and evaluation has influence on usage of allocated funds and record keeping.

7. Availability and functionality of physical facilities and school hygiene have bearing fruit of monitoring system.

8. The key resolution of the story stood to find usefulness of monitoring system on schools of Punjab.

9. There is a well-defined set of Standard of Operating Procedures (SOPs) of monitoring and those SOPs are communicated to both the observers and the practitioners.

10. SOPs of monitoring are followed by field officials while making observations regarding cleanliness or conduct of assessment tests.

11. Field officials possess authoritative behaviour and weather/climate may affect objectivity of evaluation report.

12. Support of department in case of atrocity because of evaluation report is ordinary. 


\section{RECOMMENDATIONS}

Following suggestions were made based on findings and inferences of the research.

1. The criteria for monitoring and evaluation system along with mode of reporting may be revised. School teachers have also suggested that there must be an orientation of observers and participants of monitoring.

2. The indicator scheme may be revised, and only ground situations may be included and considered for monitoring and evaluation purpose.

3. There must be an improved mechanism for counter checking of the field officials. As in TPV management the chain of hierarchy consists of a few numbers. There are DMO, SDP, DP and MEAs only. And only MEAs are field officials. DMO must visit near 6o schools every month which is very small number. So, there should be a third-party validation for monitoring officials as well.

\section{References}

Ali, N., Sharma, S., \& Zaman, A. (2017). School culture and school effectiveness: secondary schools in Pakistan. MOJEM: Malaysian Online Journal of Educational Management, 4(4), 50-65.

Bartle, P. (2010). Monitoring and Evaluation, How and How Well Objectives are Being Reached. www.scn.org/cmp/modules/mon-int.htm dated 21/1/2010.

Bolman,L., and Deal, T. (2008) Reframing Organizations(4th Ed). San Francisco: Jossey-Bass Publishers.

Cohen, L., Manion, L. \& Morrison, K. (2011). Research methods in education. 7th Ed. London: Routledge

Collins, J. W., \& O'Brien, N. P. (2011). The Greenwood dictionary of education. ABC-CLIO

Department of Planning, Monitoring and Evaluation. 2014. Discussion Document Performance Monitoring and Evaluation: Principles and Approach. Pretoria: Department of Planning, Monitoring and Evaluation.

Devolution Plan (2000), Govt. of Punjab, Lahore.

Gorgens, M, \& Kusek, J.Z. (2009). Making Monitoring and Evaluation Systems Work: A Capacity Development Toolkit. Washington D.C, World Bank.

Handbook for Inspection of Education Institutions, Ministry of Education Science and Technology. (2000).

International Monetary Fund. 2015a. "IMF Surveillance." Factsheet, April 13. http://www.imf. org/external/np/exr/facts/surv.html

Kusek, J. Z., \& Rist C. R. (2004). Ten steps to a Results-Based Monitoring and Evaluation System. Washington DC, World Bank.

Mahmood, D. Z. (2017). Comparison of Internal and External Monitoring Systems in Term of Students' Attendance, Enrollment and Retention in Punjab Education Department-Pakistan. Journal of Applied Environmental and Biological Sciences, 7(8)58-67, .

Mertens, D. M. (2005). Research and Evaluation in Education and Psychology. Sage Publications. London. pp 45- 47

Noh, H. J. 2006. Policy Evaluation. 2nd ed. Bupmunsa. Seoul, Korea

Orodho, J.A. (2008). Techniques of Writing Research Proposals and reports in Education and Social Sciences. Bureau of Educational Research. Kenyatta University, Nairobhi, Kenya.

Papay, J. P. (2012). Refocusing the debate: Assessing the purposes and tools of Teacher evaluation. Harvard Educational Review, 82(1), 123-141,167. doi:10.17763/haer.82.1. v40po833345w6384

Price, H. (2012). Principal-teacher interactions: How affective relationships shape principal and teacher attitudes. Educational Administrators Quarterly, 48(1), 39-85. 
doi:10.1177/0013161X11417126

Shah, D. (2009). Monitoring the Quality of Secondary Education in Context of Decentralization in Pakistan. Lahore: Bulletin of Education and Research, June Vol. 31. No. 1. pp1-25. IER, University of the Punjab.

UNAIDS (2008). Organizing Framework for a Functional National HIV Monitoring and Evaluation System. Geneva.

UNEP (2010). Roadmap for Effective Performance Monitoring at a Lower Cost World Bank Evaluation, Monitoring and Quality Neustar Inc.www.worldbank.org/evaluation/ dated 12/05/2010.

Willms, D. J. (2000). Monitoring School Performance for Standard Based Reforms. Retrieved on April 5, 2012 from http: www.infomaworld.com.

Zhou, G., \& Hardlife, Z. (2013). Interrogating the trajectory of Zimbabwe national budgeting. Global Business and Economics Research. 